Jérôme Pellet • Benedikt R. Schmidt

Fabien Fivaz • Nicolas Perrin · Kurt Grossenbacher

\title{
Density, climate and varying return points: an analysis of long-term population fluctuations in the threatened European tree frog
}

Received: 7 October 2005 / Accepted: 27 March 2006/Published online: 24 May 2006

(C) Springer-Verlag 2006

\begin{abstract}
Experimental research has identified many putative agents of amphibian decline, yet the populationlevel consequences of these agents remain unknown, owing to lack of information on compensatory density dependence in natural populations. Here, we investigate the relative importance of intrinsic (density-dependent) and extrinsic (climatic) factors impacting the dynamics of a tree frog (Hyla arborea) population over 22 years. A combination of log-linear density dependence and rainfall (with a 2-year time lag corresponding to development time) explain $75 \%$ of the variance in the rate of increase. Such fluctuations around a variable return point might be responsible for the seemingly erratic demography and disequilibrium dynamics of many amphibian populations.
\end{abstract}

Keywords Amphibian - Density dependence · Population fluctuations - Population regulation . Population viability analysis · Model selection · Weather

Communicated by Anssi Laurila

J. Pellet $(\bowtie) \cdot$ N. Perrin

Laboratory for Conservation Biology,

Department of Ecology and Evolution, University of Lausanne,

Biology Building, 1015 Dorigny, Switzerland

E-mail: jerome.pellet@amaibach.ch

Present address: J. Pellet

Center for Conservation Biology,

Department of Biological Sciences, Stanford University,

Stanford, CA 94305, USA

B. R. Schmidt · F. Fivaz

KARCH, Naturhistorisches Museum,

Bernastrasse 15, 3005 Bern, Switzerland

B. R. Schmidt

Zoologisches Institut, Universität Zürich,

Winterthurerstrasse 190, 8057 Zürich, Switzerland

K. Grossenbacher

Abteilung Wirbeltiere, Naturhistorisches Museum,

Bernastrasse 15, 3005 Bern, Switzerland

\section{Introduction}

There is an increasing interest among conservation biologists to learn about the effects of density dependence on life history traits and the dynamics of natural populations (Grant 1998; Forbes and Calow 2002; Vonesh and De la Cruz 2002; Henle et al. 2004). This is because the response of a natural population to negative anthropogenic impacts, such as habitat loss, pesticides, or harvesting, depends crucially upon density-dependent population responses (Sutherland and Norris 2002). While anthropogenic impacts often only affect a single life history stage or vital rate, population-level responses (e.g., population growth rate) are harder to predict (McPeek and Peckarsky 1998; Biek et al. 2002; Forbes and Calow 2002), especially because density dependence may buffer against such negative impacts (Forbes and Calow 2002; Vonesh and De la Cruz 2002). Thus, even though the study of density (in-)dependence began decades ago (Turchin 1995), it remains important to assess the relative importance of density dependence patterns for population growth (Sutherland 1996; Bjørnstad and Grenfell 2001; Lande et al. 2003) and to evaluate whether these patterns can and do in fact compensate for anthropogenic mortality (Pedersen et al. 2004; Govindarajulu et al. 2005; Rohr et al. 2006).

Amphibians are one group of animals where a better understanding of population-level processes, including density dependence, is necessary (Beebee and Griffiths 2005; Schmidt et al. 2005). This is because amphibians are declining globally for a variety of reasons acting at various spatial scales (Alford and Richards 1999; Houlahan et al. 2000; Collins and Storfer 2003; Stuart et al. 2004). Yet, the evidence for and against many of the proposed mechanisms for population declines is based largely on experimental studies that focused on vital rates of single life history stages (Beebee and Griffiths 2005), and most studies did not include density dependence or other factors that may dampen or enhance the effects of mortality, such as carry-over or time-lagged 
effects (Pahkala et al. 2001; Rohr and Palmer 2005). Even though there is good evidence for density independence in some population studies (Jaeger 1980; Beebee et al. 1996; Semlitsch et al. 1996; Grafe et al. 2004), there is also substantial evidence for density dependence in both the aquatic and subsequent terrestrial stages (Jaeger 1980; Smith 1983; Petranka 1989; Berven 1990; Van Buskirk and Smith 1991; Altwegg 2003). Both density-dependent and density independent processes can contribute to population declines in amphibians (Jaeger 1980). Hence, it is unknown whether the effects of factors extrinsic to the population (e.g., pollutants, habitat deterioration, climate change) on tadpoles or adults translate into effects on population growth and ultimately population declines (Vonesh and De la Cruz 2002).

Research into amphibian population declines should adopt a step-by-step analysis incorporating long-term observations, experiments, and models for investigating how any specific anthropogenic stressor affects the population dynamics (Blaustein et al. 2004). Despite the obvious importance of time series analyses in this process, they are still rare in amphibian ecology (Semlitsch et al. 1996; Meyer et al. 1998), and consequently amphibians with their complex life cycles are not included in recent reviews of animal population dynamics (Bjørnstad and Grenfell 2001; Lande et al. 2003; Turchin 2003).

Here, we present an analysis of a long-term time series (22 years) of an isolated population of the European tree frog (Hyla arborea L., 1758). The population that we studied was not declining. Our goal was therefore not to explain a specific decline or the causes thereof, but rather to contribute to a better understanding of amphibian population dynamics that should be useful for amphibian conservation biology and population ecology in general. The time series analysis allowed us to evaluate the relative importance of intrinsic density dependence and extrinsic factors (i.e., weather), either alone or in combination, for population growth rate (Dennis and Taper 1994; Dennis and Otten 2000; Burnham and Anderson 2002). Thus, the first goal of the analysis was to answer the question whether the dynamic of the population was driven by intrinsic density dependence, extrinsic factors, or both. This question matters because we wanted to know whether density dependence could buffer the population against extrinsic perturbations. The second goal was to evaluate which type of density dependence was operating (Saitoh et al 1997), namely linear (Ricker 1954) or log-linear (Gompertz 1825). Because the type of density dependence strongly affects predictions of population models (Henle et al. 2004), such knowledge should greatly enhance the value of predictive amphibian population models. This would allow a feedback from time series analysis to population models and thereby allow closing the loop between experiments, observational studies, and population models (Werner 1998; Blaustein et al. 2004). The third goal was to investigate the mechanisms behind the seemingly erratic fluctuations that often characterize amphibian populations (Marsh and Trenham 2001; Green 2003) and may render them especially vulnerable to local and global extinction (Leigh 1981; Schoener and Spiller 1992; Inchausti and Halley 2003).

\section{Materials and methods}

\section{Tree frog monitoring}

The European tree frog is listed as "near threatened" in the global IUCN Red List, and is highly vulnerable in most of its distribution range (IUCN 2004), including Switzerland where the status on the Swiss Red List is "endangered" (Schmidt and Zumbach 2005). H. arborea first breeds at 2 years of age and has a life expectancy of 5-6 years (Friedl and Klump 1997). Tadpole growth and juvenile metamorphosis usually take place between early June and late September. Juveniles disperse before the first night frosts to their terrestrial overwintering habitats (Stumpel 1993), where they will remain until late March. As with most frogs and toads, males of the European tree frog exhibit a conspicuous breeding behavior by calling from pond shores to attract gravid females (Giacoma et al. 1993). Counts of calling males is considered an appropriate technique for evaluations of tree frog population density (Carlson and Edenhamn 2000; Tester 1993) and is one of the most widely used methods to assess population size in anuran populations (Heyer et al. 1994). Visiting ponds regularly during the breeding season (mid-March-late May in Switzerland; Pellet et al. 2004) provides several counts of calling males, from which the highest value for a given year is generally used as an index of breeding population size (Tester 1993; Edenhamn 1996; Carlson and Edenhamn 2000; Schmidt and Pellet 2005).

We studied an isolated population in western Switzerland (Lerchenfeld near Thun, $46^{\circ} 45^{\prime} \mathrm{N}, 7^{\circ} 35^{\prime} \mathrm{E}$ ) from 1979 until 2004. Calling males were counted between one and four times $($ mean $=1.5)$ during the season by the same observer ( $\mathrm{K}$. Grossenbacher) in all years. The maximum count was used for analysis. In our population, breeding choruses were small, making it easy to accurately count individual calling males . We assume that the proportion of satellite males, the mean time spent at the pond, and the overall probability of breeding remained roughly constant through years. Because new breeding ponds were created in the area in the winter of 2000 , the dataset was restricted to the time frame where carrying capacity of the habitat was expected to have remained stable (1979-2000, thus reducing it to a 22-year-long time series; Fig. 1).

Statistical analysis and candidate models

We used standard statistical models developed for inference from short time series developed by Dennis 


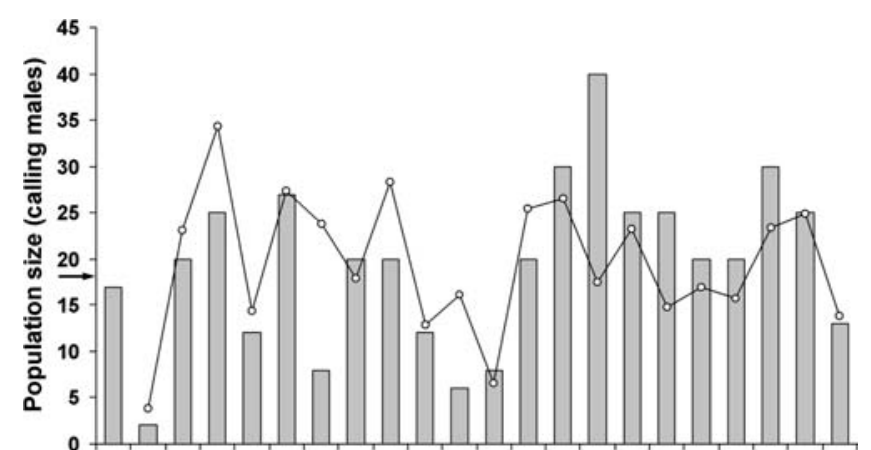

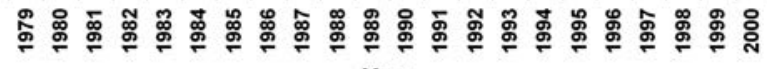

Fig. 1 Tree frog (Hyla arborea) calling males counts in Lerchenfeld from 1979 to 2000 (bars) and expected return point (dots). The return points are based on model $\mathrm{H} 10$ which has an $\mathrm{AIC}_{\mathrm{c}}$ weight of 0.980 (Table 1). The arrow on the $y$-axis indicates the position of the mean return point (based on model H10)

and Taper (1994) and Dennis and Otten (2000). They are of the general form:

$\ln \left(\frac{N_{t+1}}{N_{t}}\right)=a+b N_{t}+c W_{t}+\sigma Z_{t}$,

where $N_{t}$ is population size at time $t, W_{t}$ is a climatic covariate, $Z_{t}$ is a normal $(N \sim 0,1)$ random noise variable, and $a, b, c$ and $\sigma$ are the coefficients to be estimated. Dennis and Taper (1994) provide a detailed account of the properties of these models.

We built a set of candidate models and used information-theoretic model selection to determine which model describes the data best (Burnham and Anderson 2002). We first built a density independent null model which assumes stochastic exponential growth or decline, where slopes of $N_{t}(b)$ and $W_{t}(c)$ in Eq. 1 were constrained to be zero (model H0; Dennis and Taper 1994). We then tested for linear and loglinear density dependence (Saitoh et al. 1997). The linear function between growth rate $\left(\ln \left(N_{t+1} / N_{t}\right)\right)$ and $N_{t}$ corresponds to Ricker's (1954) density dependence model (model H1), while the loglinear model is obtained by replacing $N_{t}$ in the right-hand part of Eq. 1 with the log-transformed abundance index $X_{t}=\ln \left(N_{t}\right)$ (Gompertz 1825; Saitoh et al. 1997, model H2). The third group of candidate models tested the effect of climatic variables.

The first climatic model (H3) tests the hypothesis that rainfall during the breeding season (from April to July) affects adult breeding probabilities and thus positively affects observed population growth rate (e.g., Semlitsch 1985). Similarly, the hypothesis under our second climatic model ( $\mathrm{H} 4)$ is that rainfall at year $t-2$ positively influences population growth rate with a 2-year time-lag which is the time to sexual maturity. Rainfall could either affect breeding population size as under model $\mathrm{H} 3$ or it may affect tadpole development (e.g., Reading and Clarke 1999; Reading 2003). The third climatic model (model H5) represents the hypothesis that population growth rate is positively affected by pond water level during the period of tadpole development. The underlying hypothesis is that water level reflects pond volume which in turn is supposed to reflect the carrying capacity of the pond for tadpoles (e.g., Pearman 1993) which may positively affect population growth. Since the pond under study is located close to the river Aare $(<50 \mathrm{~m})$ and shares its water table, we used the mean river water level from April to July (with a 2-year lag which is the time to maturity). Both rainfall and water level are weakly correlated by $13 \%$, suggesting that pond water level is not influenced by atmospheric precipitation. The fourth climatic model (model H6) tests the effect of winter temperature (October-March) on population growth rate. Cold winters are known to negatively affect the survival of adult frogs (e.g., Anholt et al. 2003). Mean temperatures $\left({ }^{\circ} \mathrm{C}\right)$ during winter months (October through March) and total amount of rainfall $(\mathrm{mm})$ during spring and summer (April through July) were calculated for each year. For rainfall and temperature, we assumed a non-linear response of population growth rate and thus square-transformed both variables. Climatic data were provided by MeteoSwiss (Payerne weather station: $\left.46^{\circ} 49^{\prime} \mathrm{N}, 6^{\circ} 56^{\prime} \mathrm{E}\right)$. Data on the river Aare water level (untransformed monthly means) were provided by the Swiss Federal Office for Water and Geology.

The fourth group of models represented the hypotheses that both intrinsic (density) and extrinsic (weather) variables affect population growth (model H7-H14). These candidate models combined density and weather variables as shown in Table 1.

We used the second-order Akaike information criterion $\left(\mathrm{AIC}_{\mathrm{c}}\right.$; Hurvich and Tsai 1989) and Akaike weights (a posterior model probability; Burnham and Anderson 2002) for ranking candidate models, and $R^{2}$ to estimate the proportion of variance explained. The analysis was implemented in the statistical package $\mathrm{R}$ ( $\mathrm{R}$ Development Core Team 2004).

\section{Results}

All 15 candidate models, parameter estimates (Eq. 1), model selection criteria and $R^{2}$ are presented in Table 1 , in increasing $\mathrm{AIC}_{\mathrm{c}}$ order. Models that include both density (Ricker or Gompertz type) and rainfall at time $t-2$ perform best among our candidate models with a cumulated weight of 0.998. Gompertz-type density dependence was far better supported by the data than Ricker-type density dependence (evidence ratio $=54$; Burnham and Anderson 2002, p. 77). The best model thus reads:

$\ln \left(\frac{N_{t+1}}{N_{t}}\right)=a+b \ln \left(N_{t}\right)+c W_{t}$, 
Table 1 Model selection and parameter estimates of all candidate models

\begin{tabular}{|c|c|c|c|c|c|c|c|c|c|c|c|c|}
\hline & Predictors & $\begin{array}{l}\text { Type of } \\
\text { density } \\
\text { dependence }\end{array}$ & Intercept & $\begin{array}{l}\text { Density } \\
\text { slope }\end{array}$ & $\begin{array}{l}\text { Rain } \\
\text { slope }\end{array}$ & $\begin{array}{l}\text { Temp. } \\
\text { slope }\end{array}$ & $\begin{array}{l}\text { Water } \\
\text { level } \\
\text { slope }\end{array}$ & $\sigma$ & $\begin{array}{l}R^{2} \\
(\%)\end{array}$ & $\mathrm{AIC}_{\mathrm{c}}$ & $\Delta \mathrm{AIC}_{\mathrm{c}}$ & $w$ \\
\hline H10 & $\begin{array}{l}\text { Density and } \\
\text { rainfall }(t-2)\end{array}$ & Gompertz & 4.036 & -1.035 & $-8.23 \mathrm{E}-6$ & - & - & 0.1917 & 75 & 34.314 & 0.000 & 0.980 \\
\hline H9 & $\begin{array}{l}\text { Density and } \\
\text { rainfall }(t-2)\end{array}$ & Ricker & 2.274 & -0.060 & $-8.59 \mathrm{E}-6$ & - & - & 0.2810 & 64 & 42.352 & 8.0382 & 0.018 \\
\hline H12 & $\begin{array}{l}\text { Density and } \\
\text { water level }\end{array}$ & Gompertz & 872.236 & -1.188 & - & - & -1.582 & 0.3900 & 50 & 47.801 & 13.487 & 0.001 \\
\hline H8 & $\begin{array}{l}\text { Density and } \\
\text { rainfall }(t)\end{array}$ & Gompertz & 1.894 & -0.902 & $5.866 \mathrm{E}-6$ & - & - & 0.3783 & 51 & 48.592 & 14.278 & 0.001 \\
\hline $\mathrm{H} 2$ & Density & Gompertz & 2.745 & -0.955 & - & - & - & 0.4518 & 42 & 49.576 & 15.262 & 0.000 \\
\hline H14 & $\begin{array}{l}\text { Density and } \\
\text { temperature }\end{array}$ & Gompertz & 2.756 & -0.957 & - & -0.003 & - & 0.4518 & 42 & 52.321 & 18.006 & 0.000 \\
\hline H7 & $\begin{array}{l}\text { Density and } \\
\text { rainfall }(t)\end{array}$ & Ricker & 0.174 & -0.049 & $6.53 \mathrm{E}-6$ & - & - & 0.4693 & 39 & 53.121 & 18.807 & 0.000 \\
\hline H5 & Water level & - & -177.840 & - & - & - & 0.324 & 0.7700 & 0 & 53.266 & 18.952 & 0.000 \\
\hline H11 & $\begin{array}{l}\text { Density and } \\
\text { water level }\end{array}$ & Ricker & 858.718 & -0.069 & - & - & -1.562 & 0.5050 & 35 & 53.266 & 18.952 & 0.000 \\
\hline H1 & Density & Ricker & 0.997 & -0.051 & - & - & - & 0.5607 & 28 & 54.11 & 19.796 & 0.000 \\
\hline H4 & Rainfall $(t-2)$ & - & 0.927 & - & $-7.31 \mathrm{E}-6$ & - & - & 0.5670 & 27 & 54.345 & 20.031 & 0.000 \\
\hline H13 & $\begin{array}{l}\text { Density and } \\
\text { temperature }\end{array}$ & Ricker & 0.939 & -0.050 & - & 0.024 & - & 0.5591 & 28 & 56.797 & 22.483 & 0.000 \\
\hline $\mathrm{H} 3$ & Rainfall $(t)$ & - & -0.869 & - & $7.21 \mathrm{E}-6$ & - & - & & 14 & 57.596 & 23.282 & 0.000 \\
\hline $\mathrm{H} 0$ & Random walk & - & -0.013 & - & - & - & - & 0.7738 & 0 & 58.422 & 24.107 & 0.000 \\
\hline H6 & Temperature & - & -0.142 & - & - & 0.101 & - & 0.7443 & 4 & 60.061 & 25.747 & 0.000 \\
\hline
\end{tabular}

Models are ranked in an increasing $\mathrm{AIC}_{\mathrm{c}}$ order. Type refers to the form of density dependence

$w$ is the Akaike weight of the model

and explains a large part of the variance $\left(R^{2}=75 \%\right)$. Models including both density dependence effects and all three other climatic covariates (rainfall at time $t$, water level and winter temperatures) were weakly supported by the data, while models including density only or environmental covariates only had virtually no support from the data (all Akaike weights <0.002).

As expected under the hypothesis of density dependence, the effect of density on population growth rate was negative (Table 1); the stronger support for the Gompertz model suggests that density dependence in tree frogs is loglinear. Rainfall at time $t-2$ negatively influenced population growth rate (Table 1).

Under deterministic settings, the negative relationship between density and population growth rate would make the population stabilize at its carrying capacity. Under stochastic settings, this capacity behaves as a return point, around which the population fluctuates (Dennis and Taper 1994). In the population under study, the return point is itself fluctuating owing to variance in extrinsic factors (rainfall). The return point can be computed by setting to zero the right-hand side of Eq. 2 as

$R_{t}=\exp \left[\frac{-\left(\hat{a}+\hat{c} W_{t}\right)}{\hat{b}}\right]$

with $W_{t}$ being the total amount of rainfall 2 years before surveys; $\hat{a}, \hat{b}, \hat{c}$ being the estimated intercept and coefficients (Dennis and Otten 2000). The return point, $R_{t}$, fluctuates between 4 and 34 callers depending on the amount of rainfall 2 years before (rounded to the nearest integers; Fig. 1). The mean return point

$\hat{R}=\exp \left[\frac{-(\hat{a}+\hat{c} \bar{W})}{\hat{b}}\right]$

(where, $\bar{W}$ is the mean amount of rainfall during the study interval), is 18 (to the nearest integer).

\section{Discussion}

Our results show that the magnitude of population fluctuation in the European tree frog is affected by both intrinsic and extrinsic factors. Hence, the population fluctuates around a return point and the extrinsic factor causes the return point to fluctuate itself. While there is abundant evidence that density and/or extrinsic factors affect single vital rates or life cycle stages (e.g., Smith 1983; Petranka 1989; Berven 1990; Van Buskirk and Smith 1991; Beebee et al. 1996; Anholt et al. 2003; Altwegg 2003; Reading 2003; Grafe et al. 2004), our study is one of the few to show that these factors also affect population growth rate (e.g., Jaeger 1980; Semlitsch et al. 1996; Meyer et al. 1998).

Our best model suggests a negative effect of rainfall on population size, which runs counter to our expectations of a positive effect of rainfall on adult reproduction and/or larval development. However, it should be underlined that species normally exhibit non-monotonic, unimodal responses to environmental gradients (in fact, 
this is one of the foundations of the ecological niche), so that negative effects are expected above some optimal value. Future research should focus on capturing a wider part of the rainfall gradient, and test curvilinear responses. For the time being, we refrain from speculating about biological mechanisms a posteriori.

The large variance $(75 \%)$ explained by our model is worth underlining. Little scope is left for alternative environmental variables or for demographic stochasticity, which is somewhat surprising given the small size of the study population.

The result that density dependence matters has important implications when modeling structured demographic amphibian (meta)populations. So far, most models deal rather simply with density dependence. Conroy and Brook (2003), Griffiths (2004) and Hatfield et al. (2004) included ceiling type density dependence when modeling population and metapopulation dynamics. Since the results of population viability analyses may critically depend on the way density dependence is modeled (Henle et al. 2004), we believe that incorporating linear and/or loglinear density dependence is a key to improve these population models.

Density affects population growth rate directly, but it also acts in combination with lagged climatic variables. This might be seen as good news for this threatened species since density dependence is known to buffer small populations against extinction (Henle et al. 2004). However, Gompertz-type density dependence will also lead to a lognormal distribution of population size (Halley and Inchausti 2002) which in turn leads to a higher extinction risk (Halley and Inchausti 2002; Lande et al. 2003). This is even more the case when the amplitude of population fluctuation is wide (Leigh 1981; Schoener and Spiller 1992; Inchausti and Halley 2003). Populations are likely to show very large amplitude of fluctuations when the return point around which they fluctuate is fluctuating itself. In the case of the tree frog population we analyzed, the return point was not fixed $\left(\hat{R}_{t}=18\right)$ but varying through time $\left[R_{t} \subset(4 ; 34)\right.$; Fig. 1$\left.)\right]$. It is therefore no surprise that populations of the tree frog are very likely to go extinct, especially when small (Carlson and Edenhamn 2000; Schmidt and Pellet 2005).

If the dynamics of a natural population are driven by both intrinsic and extrinsic factors, then the likely effect of a novel anthropogenic stressor is not easy to predict. The population may or may not be able to compensate for additional mortality; potential compensation is determined by the strength of density dependence. An extrinsic factor could lead to a population decline if it causes the return point to decline or it may lead to stronger fluctuations. Under either scenario, demographic or environmental stochasticity may then cause the population to collapse and go extinct.

Our evidence for density dependence contrasts with other studies on the population dynamics of amphibians breeding in temporary ponds. Pechmann and Wilbur (1994) and Alford and Richards (1999) argued that the dynamics of anurans breeding in temporary ponds is largely driven by stochastic, density-independent variation in recruitment. Detailed long-term studies have indeed found support for strong temporal variation in recruitment (e.g., Shoop 1974; Berven 1990; Semlitsch et al. 1996). Green (2003), however, argued that this model for amphibian population dynamics is unlikely to be general because positive and negative population growth rates were equally common. Population fluctuations driven by stochastic variation in recruitment, such as under the models of Pechmann and Wilbur (1994) and Alford and Richards (1999), would not show such a pattern (Houlahan et al. 2001; Green 2003). The distribution of population growth rates as described by Green (2003) is consistent, however, with fluctuations around a return point.

Varying return points under the influence of extrinsic and intrinsic factors may provide a general explanation for the seemingly erratic fluctuations that often characterize amphibian populations (Green 2003). Population dynamics might appear driven by stochasticity, but still be determined by intrinsic or extrinsic factors. This should induce fluctuations that go beyond those caused by demographic stochasticity alone, leading to frequent local extinctions (Leigh 1981; Schoener and Spiller 1992; Inchausti and Halley 2003). Rescue effects are required in such cases for the regional persistence of metapopulations, since recolonization events must balance local extinctions. Evidence is emerging that dispersal in amphibians may not be as uniformly limited as previously thought (Smith and Green 2005), but current levels may not suffice in present-day fragmented landscapes if the environmental correlates responsible for the fluctuations in return point synchronize population dynamics across large scales (Bjørnstad et al. 1999). Landscape-level studies of habitat connectivity and environmental autocorrelations should complement analyses of local dynamics, if conclusions are to be drawn in terms of viability prospects.

Acknowledgements This work was funded by the Swiss Federal Office for Environment, Forest and Landscape, the Center for Fauna and Nature Conservation (Canton Vaud), and the MAVA Foundation. The Swiss Federal Office for Water and Geology provided data on the river Aare water level. We thank Lori-Jayne Lawson Handley and Jason Rohr for comments on the manuscript.

\section{References}

Alford RA, Richard SJ (1999) Global amphibian declines: a problem in applied ecology. Annu Rev Ecol Syst 30:133-165

Altwegg R (2003) Multistage density dependence in an amphibian. Oecologia 136:46-50

Altwegg R, Reyer HU (2003) Patterns of natural selection on size at metamorphosis in water frogs. Evolution 57:872-882

Anholt BR, Hotz H, Guex G, Semlitsch RD (2003) Overwinter survival of Rana lessonae and its hemiclonal associate Rana esculenta. Ecology 84:391-397

Beebee TJC, Denton JS, Buckley J (1996). Factors affecting population densities of adult natterjack toads Bufo calamita in Britain. J Appl Ecol 33:263-268 
Beebee TJC, Griffiths RA (2005) The amphibian decline crisis: a watershed for conservation biology? Biol Conserv 125:271-285

Berven KA (1990) Factors affecting population fluctuations in larval and adult stages of the wood frog (Rana sylvatica). Ecology 71:1599-1608

Biek R, Funk WC, Maxell BA, Mills LS (2002) What is missing in amphibian decline research: insights from ecological sensitivity analysis. Conserv Biol 16:728-734

Bjørnstad ON, Grenfell BT (2001) Noisy clockworks: time series analysis of population fluctuations on animals. Science 293:638-643

Bjørnstad ON, Ims RA, Lambin X (1999). Spatial population dynamics: analyzing patterns and processes of population synchrony. Trends Ecol Evol 14:427-432

Blaustein AR, Han B, Fasy B, Romansic J, Scheessele EA, Anthony RG, Marco A, Chivers DP, Belden LK, Kiesecker JM, Garcia T, Lizana M, Kats LB (2004) Variable breeding phenology affects the exposure of amphibian embryos to ultraviolet radiation and optical characteristics of natural waters protect amphibians from UV-B in the U.S. Pacific northwest: comment. Ecology 85:1747-1754

Burnham KP, Anderson DR (2002) Model selection and multimodel inference. Springer, Berlin Heidelberg New York

Carlson A, Edenhamn P (2000) Extinction dynamics and the regional persistence of a tree frog metapopulation. Proc R Soc Lond B 267:1311-1313

Collins JP, Storfer A (2003) Global amphibian declines: sorting the hypotheses. Divers Distrib 9:89-98

Conroy SDS, Brook BW (2003) Demographic sensitivity and persistence of the threatened white- and orange-bellied frogs of Western Australia. Popul Ecol 45:105-114

Dennis B, Taper ML (1994) Density dependence in time series observations of natural populations: estimation and testing. Ecol Monogr 64:205-224

Dennis B, Otten MRM (2000) Joint effects of density dependence and rainfall on abundance of San Joaquin kit fox. J Wildl Manage 64:388-400

Edenhamn P (1996) Spatial dynamics of the European tree frog (Hyla arborea) in a heterogeneous landscape. Dissertation, Department of Conservation Biology, Swedish University of Agricultural Sciences

Forbes VE, Calow P (2002) Population growth rate as a basis for ecological risk assessment of toxic chemicals. Phil Trans R Soc B 357:1299-1306

Friedl TWP, Klump GM (1997) Some aspects of population biology in the European tree frog, Hyla arborea. Herpetologica 53:321-330

Giacoma C, Kozar T, Pavignano I (1993). Ethological aspects of the biology of Hyla arborea. In: Stumpel AHP, Tester U (eds) Ecology and conservation of the European tree frog. Proceedings of the 1st international workshop on Hyla arborea, Institute for Forestry and Nature Research, Wageningen, pp 21-28

Gompertz B (1825) On the nature of the function expressive of the law of human mortality, and on a new mode of determining the value of life contingencies. Phil Trans R Soc B 115:513-585

Govindarajulu P, Altwegg R, Anholt BR (2005) Matrix model investigations of invasive species control: bullfrogs on Vancouver island. Ecol Appl 15:2161-2170

Grafe T, Kaminsky SK, Bitz JH, Lüssow H, Linsenmair KE (2004) Demographic dynamics of the afro-tropical pig-nosed frog, Hemisus marmoratus: effects of climate and predation on survival and recruitment. Oecologia 141:40-46

Grant A (1998) Population consequences of chronic toxicity: Incorporating density dependence into the analysis of life table response experiments. Ecol Model 105:325-335

Green DM (2003) The ecology of extinction: population fluctuation and decline in amphibians. Biol Conserv 111:331-343

Griffiths RA (2004) Great Crested Newts (Triturus cristatus) in Europe. In: Akçakaya RH, Burgman MA, Kindvall O, Wood CC, Sjögren-Gulve P, Hatfield JS, McCarthy MA (eds) Species conservation and management. Oxford University Press, Oxford, pp 281-291
Halley J, Inchausti P (2002) Lognormality in ecological time series. Oikos 99:518-530

Hatfield JS, Price AH, Diamond DD, True CD (2004) Houston toad (Bufo houstonensis) in Bastrop County, Texas: need for protecting multiple subpopulations. In: Akçakaya RH, Burgman MA, Kindvall O, Wood CC, Sjögren-Gulve P, Hatfield JS, McCarthy MA (eds) Species conservation and management. Oxford University Press, Oxford, pp 292-298

Henle K, Sarre S, Wiegand K (2004) The role of density regulation in extinction processes and population viability analysis. Biodivers Conserv 13:9-52

Heyer RW, Donnelly MA, McDiarmid RW, Hayek LAC, Foster MS (1994). Measuring and monitoring biodiversity: standard methods for amphibians. Smithsonian Institution Press, Washington

Houlahan JE, Findlay CS, Schmidt BR, Meyer AH, Kuzmin SL (2000) Quantitative evidence for global amphibian population declines. Nature 404:752-755

Houlahan JE, Findlay CS, Meyer AH, Kuzmin SL, Schmidt BR (2001) Global amphibian population declines. Nature 412:500

Hurvich CM, Tsai CL (1989) Regression and time series model selection in small samples. Biometrika 76:297-307

Inchausti P, Halley J (2003) On the relation between temporal variability and persistence time in animal populations. J Anim Ecol 72:899-908

IUCN, Conservation International, and NatureServe (2004) Global amphibian assessment. < http://www.globalamphibians.org $>$. Accessed on 17 January 2006

Jaeger RG (1980) Density-dependent and density-independent causes of extinction of a salamander population. Evolution 34:617-621

Lande R, Engen S, Sæther BE (2003) Stochastic population dynamics in ecology and conservation. Oxford University Press, Oxford

Leigh EG (1981) The average lifetime of a population in a varying environment. J Theor Biol 90:213-239

Marsh DM, Trenham PC (2001) Metapopulation dynamics and amphibian conservation. Conserv Biol 15:40-49

Meyer AH, Schmidt BR, Grossenbacher K (1998) Analysis of three amphibian populations with quarter-century long time-series. Proc R Soc Lond B 265:523-528

McPeek MA, Peckarsky BL (1998) Life histories and the strengths of species interactions: combining mortality, growth, and fecundity effects. Ecology 79:867-879

Pahkala M, Laurila A, Merilä J (2001) Carry-over effects of ultraviolet-B radiation on larval fitness in Rana temporaria. Proc R Soc Lond B 268:1699-1706

Pearman PB (1993) Effects of habitat size on tadpole populations. Ecology 74:1982-1991

Pechmann JHK, Wilbur HM (1994) Putting declining amphibian populations in perspective: natural fluctuations and human impacts. Herpetologica 50:65-84

Pedersen HC, Steen H, Kastdalen L, Brøseth H, Ims RA, Svendsen W, Yoccoz NG (2004) Weak compensation of harvest despite strong density-dependent growth in willow ptarmigan. Proc R Soc Lond B 271:381-385

Pellet J, Guisan A, Perrin N (2004) A concentric analysis of the impact of urbanization on the threatened European tree frog in an agricultural landscape. Conserv Biol 18:1599-1606

Petranka JW (1989) Density-dependent growth and survival of larval Ambystoma: evidence from whole-pond manipulations. Ecology 70:1752-1767

Pribil S, Houlahan JE (2003) Life history strategies associated with local population variability confer regional stability. Proc R Soc Lond B 270:1419-1423

R Development Core Team (2004) R: a language and environment for statistical computing. $\mathrm{R}$ foundation for statistical computing, Vienna

Reading CJ (2003) The effects of variation in climatic temperature (1980-2001) on breeding activity and tadpole stage duration in the common toad, Bufo bufo. Sci Total Environ 310:231-236 
Reading CJ, Clarke RT (1999) Impacts of climate and density on the duration of the tadpole stage of the common toad Bufo bufo. Oecologia 121:310-315

Ricker WE (1954) Stock and recruitment. J Fish Res Board Can 11:559-923

Rohr JR, Palmer BD (2005) Aquatic herbicide exposure increases salamander desiccation risk eight months later in a terrestrial environment. Environ Toxicol Chem 24:1253-1258

Rohr JR, Sager T, Sesterhenn TM, Palmer BD (2006) Exposure, postexposure, and density-mediated effects of atrazine on amphibians: breaking down net effects into their parts. Environ Health Perspect 114:46-50

Saitoh T, Stenseth NC, Bjørnstad ON (1997) Density dependence in fluctuating grey-sided vole populations. J Anim Ecol 66:14-24

Schmidt BR, Feldmann R, Schaub M. (2005) Demographic processes underlying population growth and decline in Salamandra salamandra. Conserv Biol 19:1149-1156

Schmidt BR, Pellet J (2005). Relative importance of population processes and habitat characteristics in determining site occupancy of two anurans. J Wildl Manage 69:884-893

Schmidt BR, Zumbach S (2005) Rote Liste der gefährdeten Amphibien der Schweiz. BUWAL-Reihe, Vollzug Umwelt, p 48

Schoener TW, Spiller DA (1992) Is extinction rate related to temporal variability in population size? An empirical answer for orb spiders. Am Nat 139:1176-1207

Semlitsch RD (1985) Analysis of climatic factors influencing migrations of the salamander Ambystoma talpoideum. Copeia 1985:477-489

Semlitsch RD, Scott DE, Pechmann JHK, Gibbons JW (1996) Structure and dynamics of an amphibian community: evidence from a 16-year study of a natural pond. In: Cody M, Smallwood J (eds) Long-term studies of vertebrate communities. Academic, San Diego, pp 217-248

Shoop CR (1974) Yearly variation in larval survival of Ambystoma maculatum. Ecology 55:440-444

Smith DC (1983) Factors controlling tadpole populations of the chorus frog (Pseudacris triseriata) on Isle Royale, Michigan. Ecology 64:501-510
Smith MA, Green DM (2005) Dispersal and the metapopulation paradigm in amphibian ecology and conservation: are all amphibian populations metapopulations? Ecography 28:110 128

Stumpel AHP (1993) The terrestrial habitat of Hyla arborea. In: Stumpel AHP, Tester U (eds) Ecology and conservation of the European tree frog. Proceedings of the 1st international workshop on Hyla arborea, Institute for Forestry and Nature Research, Wageningen, pp 47-54

Stuart SN, Chanson JS, Cox NA, Young BE, Rodrigues ASL, Fischman DL, Waller RW (2004) Status and trends of amphibian declines and extinctions worldwide. Science 306:1783-1786

Sutherland WJ (1996) From individual behaviour to population ecology. Oxford University Press, New York

Sutherland WJ, Norris K (2002) Behavioural models of population growth rates: Implications for conservation and prediction. Phil Trans R Soc Lond B 357:1273-1284

Tester U (1993) Methods and definitions for tree frog research. In: Stumpel AHP, Tester U (eds) Ecology and conservation of the European tree frog. Proceedings of the 1st international workshop on Hyla arborea, Institute for Forestry and Nature Research, Wageningen, pp 21-28

Turchin P (1995) Population regulation: old arguments and a new synthesis. In: Cappuccino N, Price P (eds) Population dynamics. Academic, New York, pp 19-39

Turchin P (2003) Complex population dynamics: a theoretical empirical synthesis. Princeton University Press, Princeton

Van Buskirk J, Smith DC (1991) Density-dependent population regulation in a salamander. Ecology 72:1747-1756

Vonesh JR, De la Cruz O (2002) Complex life cycles and density dependence: assessing the contribution of egg mortality to amphibian declines. Oecologia 133:325-333

Werner EE (1998) Ecological experiments and a research program in ecology. In: Resetarits WJ, Bernardo J (eds) Experimental ecology. Oxford University Press, New York pp 3-26 